\title{
Home Sweet Home? Public Financing and Inequalities in the Use of Home Care Services in Europe*
}

\author{
VINCENZO CARRIERI, $\dagger$ CINZIA Di NOVI $\ddagger$ \\ and CRISTINA ELISA ORSO§
}

$\dagger$ Department of Economics and Statistics, University of Salerno; Health, Econometrics and Data Group, University of York; RWI Research Network

(vcarrieri@unisa.it)

$\ddagger$ Department of Economics and Management, University of Pavia; Health, Econometrics and Data Group, University of York; Laboratory for Comparative Social Research (LCSR), National Research University Higher School of Economics

(cinzia.dinovi@unipv.it)

$\S$ Department of Economics, Ca' Foscari University of Venice

(cristina.orso@unive.it)

\begin{abstract}
Income-related inequalities in health care access have been found in several European countries, but little is known about the extent of needs-adjusted inequalities (inequities) in the provision of long-term care (LTC) services. This paper fills this gap: it addresses equity issues related to the provision of home

\footnotetext{
* Submitted November 2015.
}

An earlier draft of this paper was presented at the annual meeting of the Italian Health Economics Association, Venice, at the Rand Corporation Workshop on Aging, Santa Monica, and at the Workshop on Public Financing of Long-Term Care at the London School of Economics. The authors wish to thank the conference and workshop participants for their detailed and helpful comments. The authors in particular wish to thank Joan Costa-Font, Mario Ferrero, Alessandro Rosina and Francesca Zantomio for useful suggestions. They also gratefully acknowledge financial support from Fondazione Farmafactoring (Milan) through the Young Researcher Award Programme. This paper was prepared within the framework of a subsidy granted to the Higher School of Economics by the Government of the Russian Federation for the implementation of the Global Competitiveness Programme. The usual disclaimer applies.

Keywords: inequality, horizontal inequity, long-term care insurance, home care.

JEL classification numbers: I11, I14.
\end{abstract}


care services across three macro areas in Europe that are highly heterogeneous in terms of the degree of public financing of LTC and the strength and social value of family ties. Using cross-country comparative microdata from the Survey of Health, Ageing and Retirement in Europe (SHARE), we estimate and decompose an Erreygers concentration index of the use of both paid domestic help ('unskilled' care) and personal nursing care ('skilled' care), measuring the contribution of income, need and non-need factors to overall inequality. We base the decomposition on a bivariate probit model that takes into account the interaction between formal and informal home care use. We find higher inequities in the use of unskilled home care in areas where public financing of LTC is relatively low ('Southern Europe') than in areas where the publicprivate mix of financing is more balanced ('Continental Europe'). At the same time, we do not detect inequity in 'Northern Europe', which is characterised by high public spending on universal, equitable services, including LTC public coverage. In all areas, we find informal care is a substitute for paid unskilled care among the poor, and this contributes to further skewing of the distribution of the use of formal care services towards the rich.

\section{Policy points}

- This paper addresses equity issues related to the provision of home care services across three macro areas in Europe that are highly heterogeneous in terms of the degree of public financing of long-term care (LTC) and the strength and social value of family ties.

- We find higher inequities in the use of unskilled home care in areas where public financing of LTC is relatively low (southern Europe).

- An interesting compromise that may help achieve both equity of access and public expenditure in the LTC sector is community care, which is less costly than institutional LTC and appears to be a sensible way of responding to elderly people's needs while also averting demographic and economic crisis.

\section{Introduction}

An extensive literature documents the existence of income-related inequalities in access to health care in Europe for a wide set of medical and preventive health care services. ${ }^{1}$ These inequalities persist also after controlling for the different distribution of needs across income groups, raising important ethical concerns. Indeed, the presence of needs-adjusted income-related inequalities in the use of health services represents a violation of the well-known horizontal

\footnotetext{
${ }^{1}$ For example, van Doorslaer and Wagstaff (2000), Lorant et al. (2002), van Doorslaer, Masseria and Koolman (2006), Jusot, Or and Sirven (2012) and Carrieri and Wuebker (2013).
} 
equity principle, according to which people in equal need ought to be treated equally irrespective of their income position. For this reason, several countries have undertaken systematic policy actions to measure, monitor and tackle these inequities. $^{2}$

Despite the increasing attention towards inequity in health care access, little is known about the extent and the determinants of horizontal inequity in access to long-term care (LTC) services - namely, health, social and residential services provided to chronically disabled persons over an extended period of time. This lack of evidence is troubling for at least three reasons. First, these services are more often used by the elderly, who represent a significant and growing percentage of the European population; forecasts of European demographics show that around half the population of the EU-27 countries will be aged over 50 in the year 2060, while the percentage of the population over 65 will increase from 17.4 per cent in 2010 to 30 per cent in $2060{ }^{3}$ This means that the next few decades will see increasing rates of care-dependent older people in need of LTC. ${ }^{4}$ Second, demographic and cultural trends in European countries are changing the traditional patterns of care. Although the family still acts as a strong support network for the elderly, the demographic transition, the defamilialisation process and the dramatic increase in female labour force participation have reduced the possibilities of providing care informally. The increasing demand for care, in combination with a reduced potential for informal care, is likely to result in a need to expand formal care services. ${ }^{5}$ Third, under current demographic trends, LTC will absorb a growing share of private and public resources ${ }^{6}$ and this may increase incomerelated inequalities in access to LTC services, especially in southern European countries, where the extent of LTC public insurance is relatively narrow.

In this paper, we measure and explain inequalities in the provision of formal LTC services among the European elderly (those over 65 years old) using cross-country comparative microdata from the Survey of Health, Ageing and Retirement in Europe (SHARE). Specifically, we focus on inequality in the access to home care services, which cover a wide range of needs, from homemaking and companionship to meal preparation and medication reminders to personal care services and help with the activities of daily living, such as bathing and dressing. We investigate inequalities across three macro areas in Europe using a stratification that reflects differences in the degree of

\footnotetext{
${ }^{2}$ See, for instance, the English action report - Department of Health (2009).

${ }^{3}$ Eurostat, 2012.

${ }^{4}$ The 'red herring hypothesis' (Zweifel, Felder and Meiers, 1999; Breyer and Felder, 2006; de Meijer et al., 2011) claims that time until death is one of the most significant predictors of health deterioration and the actual demand for health care services. However, ageing is also an important contributing factor to rising health needs (Seshamani and Gray, 2004; Stearns and Norton, 2004).

${ }^{5}$ Crespo and Mira, 2010; Di Novi, Jacobs and Migheli, 2015; Brenna and Di Novi, 2015.

${ }^{6}$ Costa-Font, 2010a and 2010b.
} 
public financing of LTC services and in the degree of responsibility for the provision of informal care that is generally attributed to the individual by local social norms (see Section II for more details).

Our analysis proceeds in two stages. First, we explore horizontal inequities in access to home care services, testing whether elderly individuals with the same level of need experience a difference in the level of utilisation related to their income. In order to deal with a tractable empirical model, we employ a binary variable to measure access to home care services (home care utilisation: yes or no) and we measure inequities by means of the version of the concentration index corrected for binary dependent variables by Erreygers (2009a and 2009b). Following Bonsang (2009), we consider separately two types of formal home care: skilled (nursing care) and low-skilled (paid domestic help) formal home care.

Second, we decompose the Erreygers index into the contributions of income, need and non-need factors following the method adopted by van Doorslaer, Koolman and Jones (2004) in the analysis of income-related inequalities in medical care. This decomposition technique allows us to explain the determinants of the overall income-related inequalities observed in the three European macro areas. An important novel element in our empirical strategy is that we also base the Erreygers index decomposition on a bivariate probit model with exclusion restrictions, which takes into account the reciprocal interaction between formal and informal home care, thus controlling for the potential simultaneity between formal and informal care. ${ }^{7}$

Our results, robust under different specifications of the model, reveal a clear north-south gradient. We find horizontal inequity favouring the rich in the use of paid domestic help in southern countries and substantial horizontal equity in the use of these services in northern countries.

The remainder of the paper is organised as follows. Section II describes the data. Section III illustrates the empirical model, while the results are presented and discussed in Section IV. Concluding remarks are reported in Section V. The description of the bivariate probit model, the sensitivity analysis, descriptive statistics and tables with estimation coefficients can be found in the online appendices.

\section{Data}

The individual-level data employed in this study are drawn from the second wave of the Survey of Health, Ageing and Retirement in Europe. SHARE, which is coordinated by the Munich Center for the Economics of Aging (MEA), collects detailed information on a wide variety of factors, including the health

\footnotetext{
${ }^{7}$ See also Van Houtven and Norton (2004), Bolin, Lindgren and Lundborg (2008), Bonsang (2009) and Balia and Brau (2013).
} 
status, health care access and socio-economic characteristics of people aged $50+$ in Europe.The design is based on the Health and Retirement Study (HRS) and the English Longitudinal Study of Ageing (ELSA). ${ }^{8}$

The survey information for the second wave of SHARE was collected between the end of 2006 and the summer of 2007 through computer-assisted personal interviews (CAPI) supplemented by a self-completion paper. Our analysis is based on version 2.5.0 of SHARE's second wave. ${ }^{9}$ We used data from the following 10 European countries: Austria, Belgium, Denmark, France, Germany, Greece, Italy, the Netherlands, Spain and Sweden. After careful consideration, we decided to exclude three countries that were incorporated in this wave of SHARE - namely, the Czech Republic, Poland and Switzerland. The Czech Republic and Switzerland were not included since the indicator of home care contained too many missing values. Poland was excluded since information concerning informal care and formal care received at home was not available.

Three selection criteria were imposed on the sample: (1) respondents should be 65 years of age or older; (2) respondents should not be living with their children; and (3) respondents should not permanently live in a nursing home. After correcting for missing values, the final sample included 9,239 observations. ${ }^{10}$

\section{The provision of LTC in Europe: differences between macro areas}

Previous studies have demonstrated that the use of formal and informal care services is generally dependent on two main factors: (1) societal attributes, such as the availability of public LTC insurance coverage; and (2) the strength and social value of family ties. ${ }^{11}$ Both factors are highly heterogeneous across European macro areas, and this may result in important differences in the use of such services.

The social value of family ties and the design of long-term care systems highlight where the primary responsibility for meeting care needs lies. It

\footnotetext{
${ }^{8}$ Börsch-Supan and Jürges, 2005.

${ }^{9}$ We did not use the first wave of SHARE since income is measured before taxes and transfers, while in all other waves it is measured after taxes and transfers. The two income measures are not directly comparable and, if used jointly, might produce biased estimates of income-related inequalities in LTC. This issue might be particularly severe for our empirical analysis based on cross-country data and carried out in European countries that are characterised by different tax and transfer systems. The fourth wave of SHARE has not been employed in our analysis because it does not include any information on the recourse to LTC services. We did not use the third wave as it mainly provides a retrospective analysis of respondents' behaviour and so is not comparable to other waves.

${ }^{10} \mathrm{We}$ excluded respondents living with their children since SHARE does not provide information about the method, type and importance of transfers that take place within a household (Bonsang, 2009).

${ }^{11}$ See also Bolin, Lindgren and Lundborg (2008), Crespo and Mira (2014), Brenna and Di Novi (2015) and Di Novi, Jacobs and Migheli (2015).
} 
FIGURE 1

Long-term care public expenditure (health and social components) as a share of GDP, 2011 (or nearest year)

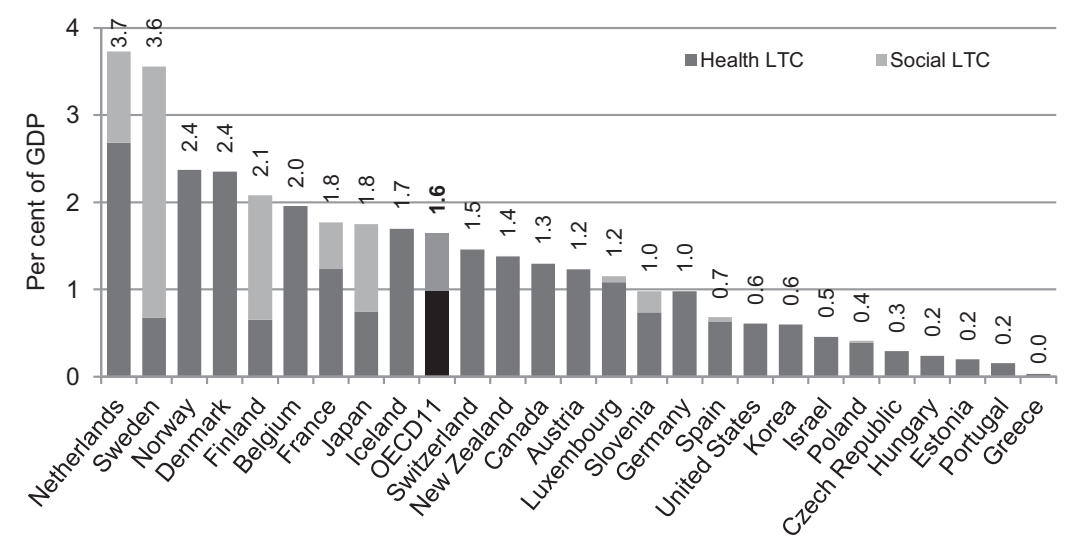

Note: The OECD average only includes the 11 countries that report health and social LTC.

Source: OECD Health Statistics 2013, https://doi.org/10.1787/health-data-en.

may lie with the individual ('Scandinavian model'), the nuclear family ('Continental model') or the extended family ('Mediterranean model'). Consistent with these differences in the share of public coverage and in the social values of family ties, we stratify our sample into three models that we label Northern, Continental and Southern European. The Northern European model includes Denmark, the Netherlands and Sweden and is characterised by a high level of public financing of LTC and individual responsibility in the provision of LTC. The Continental European model includes Austria, Belgium, France and Germany, which are characterised by moderate public financing of LTC and the responsibility of the nuclear family in the provision of LTC services. Finally, the Southern European model includes Greece, Italy and Spain, which are characterised by a low level of public financing of LTC and a high degree of responsibility of the extended family in the provision of LTC services.

OECD health data, ${ }^{12}$ which show LTC public expenditure as a share of national GDP, support our classification. Figure 1 shows that public LTC systems are most generous in the Netherlands, Sweden and Denmark, which spend respectively 3.7 per cent, 3.6 per cent and 2.4 per cent of their GDP on LTC. These countries offer universal public coverage for LTC services, and the state responsibility for providing care services for older people is greater than in other European countries. On the opposite side, Southern European

\footnotetext{
${ }^{12}$ OECD Health Statistics 2013, https://doi.org/10.1787/health-data-en.
} 
countries have a thinner formal long-term care system and formal home care network: the role of the state is minimal, and LTC financing is highly privatised. Here, the expectation is that social care will be mainly provided within the family. ${ }^{13}$ Figure 1 shows that Spain and Greece spend 0.7 per cent and a bit less than 0.1 per cent of their GDP on LTC, respectively. ${ }^{14}$ Between these two extremes lies a third cluster, the Continental countries (Austria, Belgium, France and Germany), which are characterised by moderate levels of formal and informal care provision. Continental countries show a moderate level of public expenditure on LTC as a percentage of GDP, ranging from 1 per cent in Germany to 2 per cent in Belgium.

The classification proposed here has some parallels with Esping-Andersen (1990)'s traditional classification of welfare states. Similar to his approach, we consider as a first cluster the Scandinavian/Northern group of countries, which is close to Esping-Andersen's 'social-democratic' regime cluster with high levels of state support (indeed, LTC insurance is mainly delegated to the public sector) and in which welfare coverage is universal and attempts to treat all citizens equally. Esping-Andersen groups together Austria, Belgium, France and Germany in a 'conservative' regime cluster characterised by the preservation of the status quo and its inequalities. Social rights tend to be attached to class and what one has earned by one's work effort. EspingAndersen's traditional classification also includes Italy in the conservative group, while we assigned Italy to the Southern European cluster. It seems appropriate to classify the Southern European countries as a separate cluster when attention is shifted to the care sector: countries such as Greece, Italy and Spain form a distinctive cluster due to the strong role of the extended family and lower levels of welfare services. ${ }^{15}$

\section{Empirical model}

\section{The Erreygers concentration index}

Our empirical analysis involves two basic steps. First, we explore the level of horizontal inequity in access to home care services, employing Erreygers's concentration index, and then we decompose the Erreygers index into the contributions of income, need and non-need factors to explain overall incomerelated inequalities across countries.

Income-related inequalities (and inequities) in home care use are calculated by means of a concentration index $(\mathrm{CI}):^{16}$

\footnotetext{
${ }^{13}$ See also Costa-Font and Zigante (2014).

${ }^{14}$ Data for Italy's expenditure were not available in the OECD data used in Figure 1.

${ }^{15}$ Mingione, 2001.

${ }^{16}$ Wagstaff, van Doorslaer and Paci, 1991; Wagstaff and van Doorslaer, 2000.
} 


$$
C I=\frac{2}{n \mu} \sum_{i=1}^{n} y_{i} R_{i}-1=\frac{2}{\mu} \operatorname{cov}\left(y_{i}, R_{i}\right)
$$

where $\mu$ is the average access to home care services in the sample, $n$ is the sample size, $y_{i}$ is an indicator of access to home care services by individual $i$ and $R_{i}$ designates the $i^{\text {th }}$ individual's rank within the income distribution. Equation 1 shows that the value of the CI equals twice the covariance between the indicator of home care access $\left(y_{i}\right)$ and the individual's living standard rank $\left(R_{i}\right)$, divided by the average access $(\mu)$.

In order to deal with a tractable empirical model, we employ a binary variable to measure access to home care services (home care utilisation: yes or no). ${ }^{17}$ Therefore we use the corrected version of the concentration index for bounded variables suggested by Erreygers (2009a), which satisfies the mirror condition - the invariance of the inequality index to the coding of the health care variable as 0 or $1^{18}$ - and the quasi-absoluteness property - i.e. it weights inequality constantly and independently of the average use in a country. ${ }^{19}$ This is particularly appropriate for situations in which the average use of health care strongly differs among countries, as in our case. ${ }^{20}$

\footnotetext{
${ }^{17}$ The second wave of SHARE also collects detailed information about the number of weeks (per year) and the average number of hours (per week) of personal care and domestic help received by the elderly. However, using the continuous variables in our empirical model may lead to estimation problems. First, the distribution of the hours of care appears strongly skewed on the left side: roughly 65 per cent of individuals receive fewer than three hours of care per week. Second, in order to analyse the intensive margin (hours of formal care received), we need to introduce a specific model for access to care, such as the two-part model (Duan et al., 1984), which specifies the probability of receiving care and the quantity of care received as two different processes. This model allows for the separation of the individual's behaviour into two steps: first, a decision regarding receiving some care, and second, a decision concerning the amount of care, conditional on receiving any. At the same time, the simultaneity of formal and informal care decisions and the potential unobserved heterogeneity make it necessary to control for possible endogeneity of informal care. Both issues are empirically relevant, and their combination would make the econometric exercise intractable.

${ }^{18}$ In our case, this means that the inequality index does not change if inequalities in home care utilisation are measured with respect to use (i.e. home care utilisation $=1$ ) or no use (i.e. home care utilisation $=0$ ) of home care.

${ }^{19}$ See Erreygers (2009b), Erreygers and van Ourti (2011) and Kjellsson and Gerdtham (2013).

${ }^{20} \mathrm{An}$ alternative to the Erreygers correction might be the normalisation formula proposed by Wagstaff (2005), which also has a number of desirable characteristics, including the mirror property (see Kjellsson and Gerdtham (2013)). However, the Wagstaff index is a relative inequality index that considers the same level of absolute inequality more strongly for both high and low values of home care utilisation than for medium values. In our case, one consequence of the Wagstaff measurement would be that having home care utilisation would be considered, in relative terms, more advantageous in a very high utilisation or very low utilisation society (Erreygers and van Ourti, 2011). The Erreygers index weights inequality constantly and independently of the average use in a country. In the analysis presented here, it should be kept in mind that the use of the Erreygers index affects the ranking of countries according to inequalities in home care utilisation (compared with the Wagstaff index), but not the decomposition analysis, as the percentage contribution of each explanatory variable is the same with the Erreygers index and with the Wagstaff index (van Doorslaer and van Ourti, 2011).
} 
The formula for the corrected concentration index is

$$
E(y)=\frac{4 \mu}{b_{n}-a_{n}} C I(y),
$$

where $b_{n}$ and $a_{n}$ represent the maximum and minimum of the home care access variable $y$ (in our case, 1 and 0 ), $\mu$ is the mean of the home care access variable in the population and $C I(y)$ represents the concentration index specified in equation 1.

As a second step, we decompose income-related inequalities as follows:

$$
\begin{aligned}
E I(y)= & 4\left\{\beta_{r} \bar{x}_{r} C I(x)_{r}+\sum_{n n} \beta_{n n} \bar{x}_{n n} C I(x)_{n n}+\sum_{n} \beta_{n} \bar{x}_{n} C I(x)_{n}\right. \\
& \left.+\sum_{i c} \beta_{i c} \bar{x}_{i c} C I(x)_{i c}+\operatorname{GCI}\left(\varepsilon_{i}\right)\right\},
\end{aligned}
$$

where $\bar{x}_{r}, \bar{x}_{n n}, \bar{x}_{n}$ and $\bar{x}_{i c}$ represent respectively the means of income $\left(x_{r}\right)$, nonneed variables $\left(x_{n n}\right)$, need variables $\left(x_{n}\right)$ and informal care $\left(x_{i c}\right) . C I(x)_{r}, C I(x)_{n n}$, $C I(x)_{n}$ and $C I(x)_{i c}$ are their concentration indices. $G C I\left(\varepsilon_{i}\right)$ is a residual term.

Equation 3 shows that income-related inequalities in home care use can be represented as a weighted sum of the inequalities in its determinants. The weights are represented by the regression coefficients evaluated at the means (i.e. semi-elasticities). The decomposition provides the possibility of identifying the driving factors of income-related inequalities in the use of home care services among the elderly: the higher the concentration of the determinant with respect to income $(C I)$ or the semi-elasticity, the higher the contribution.

Decomposition of the concentration index as in equation 3 is based on linear modelling of home care use. However, since the outcome variable in our application is binary, following van Doorslaer, Koolman and Jones (2004), we base the decomposition on a linear approximation based on partial effects (the $\beta \mathrm{s}$ in equation 3) estimated by a non-linear model.

In this application, the situation is further complicated by the inclusion of informal care among the dependent variables in the formal care access equation. Indeed, informal care and formal home care may be simultaneously determined. ${ }^{21}$ This could be because the receipt of informal care may be correlated with unobserved health characteristics or with unobserved preferences for care that are likely to influence the demand for home care. ${ }^{22}$ For these reasons, we computed the partial effects in equation 3 through a recursive bivariate probit model. The recursive structure of the bivariate

\footnotetext{
${ }^{21}$ Van Houtven and Norton, 2004.

${ }^{22}$ Charles and Sevak, 2005; Bonsang, 2009.
} 
probit model builds on a first structural form equation determining the receipt of formal home care and a second reduced form equation for the potentially endogenous dummy measuring the receipt of informal care; it also relies on exclusion restrictions (details of this model are provided in Appendix I online). When exogeneity cannot be rejected - i.e. the estimated correlation coefficient between equations in the bivariate probit model is not significantly different from 0 - we base the decomposition on a standard probit. In the standard probit, we employ robust standard errors by applying a HuberWhite sandwich estimator that corrects for heteroskedasticity of unknown form.

To draw inferences on the concentration indices and on the contributions of each explanatory variable, we use a non-parametric bootstrap method with 1,000 replications. The bootstrap method is adapted to reflect the stratified sampling with respect to the primary sampling unit of the SHARE survey. All computations are repeated on each resampled data set, and the variability is used to obtain standard errors.

\section{The inequality decomposition}

In order to investigate equity issues related to the provision of home care services, the model is estimated by considering separately skilled (nursing care) and low-skilled (paid domestic help) formal home care. ${ }^{23}$ Respondents were asked to report whether they made use of personal care services (i.e. help with basic activities of daily living, medical services such as wound dressing, medication, health monitoring and rehabilitation) and domestic help (lowerskilled care provided by low-skilled or unskilled workers, typically related to help in instrumental activities of daily living) in the last 12 months because of health problems. As mentioned in Section III.1, the dependent variables employed to predict the probability of receiving formal home care services in the probit / bivariate probit models are binary variables (see Table 1 later for variable definitions).

The independent variables employed to decompose income-related inequalities in home care services were categorised into three dimensions: (1) income; (2) need factors related to aspects of individuals' health status; and (3) non-need factors.

Income information is based on total annual household income, obtained by adding up its different components assessed in the questionnaire after deductions for income tax and social or national insurance contributions. It mainly comprises labour income, public pensions and income from assets. To get the annual 'equivalent household income', we adjusted for household size and composition using the following equivalence scale formula:

\footnotetext{
${ }^{23}$ See Bonsang (2009).
} 


$$
\text { Equivalent income }=\frac{\text { Family income }}{(\text { No. of adults }+(0.5 \times \text { No. of children }))^{0.5}} .
$$

Need variables include age and several measures of health status. Following Bolin, Lindgren and Lundborg (2008), we included, as measures of the need for formal care, indicators of self-perceived health, number of activity limitations, number of health conditions and number of symptoms. Concerning selfperceived health, the following standard self-assessed health (SAH) status question was asked: 'Would you say that in general your health is: excellent, very good, good, fair, poor?'. SAH was therefore measured on a five-point scale from 'excellent' (score 5) to 'poor' (score 1) and treated as an ordered categorical variable. The use of SAH as an indicator of health status is supported by evidence that shows a strong predictive relationship between people's self-rating of health and morbidity. ${ }^{24}$ Moreover, SAH correlates strongly with more complex health indices such as functional ability or indicators derived from health service use. ${ }^{25}$

We also included a continuous variable that captures the number of problems with functioning and disability. This indicator concerns self-reported difficulty in performing tasks related to mobility, strength and endurance. ${ }^{26}$ The 10 indicators of functioning ability are walking one block, climbing several flights of stairs, climbing one flight of stairs, sitting for about two hours, getting up from a chair, lifting or carrying weights over 10 pounds, stooping, kneeling or crouching, picking up a small coin from a table, reaching or extending arms, and pulling or pushing large objects.

Then we considered, among the proxies of the need for care, the number of health conditions (heart problems, high blood pressure, high cholesterol, stroke, diabetes, lung disease, asthma, arthritis, osteoporosis, cancer, ulcer, Parkinson's disease, cataracts, hip or femoral fracture, psychological problems, other). In addition to chronic diseases, we controlled for health symptoms using a continuous variable that is the sum of different symptoms that the individual suffered from during the last six months (for example, sleeping problems, falling down, persistent cough, fatigue, swollen leg and dizziness). ${ }^{27}$ The average was 2.03 symptoms, ranging from 0 to 11 . These symptoms were used as a proxy for the overall health situation of the respondent.

\footnotetext{
${ }^{24}$ Idler and Benyamini, 1997; Kennedy et al., 1998.

${ }^{25}$ Undén and Elofsson, 2006.

${ }^{26}$ Nagi, 1976.

${ }^{27}$ Functioning and health conditions in SHARE are measured on a binary scale: a specific condition can either occur or fail to occur, but no intensity is assessed. Chronic medical conditions often occur in combination, as co-morbidities, rather than as isolated conditions. Considering the overall number of health impairments allows us to obtain a comprehensive measure of the health status of respondents, which takes into account conditions existing simultaneously. This is an approach followed by many other papers - see, among others, Bolin, Lindgren and Lundborg (2008), Denton and Spencer (2010) and Di Novi et al. (2015).
} 
Non-need variables included education, marital status and residential area. Education was measured by the ISCED-97 classification. Three levels of education were considered: (1) low education - no educational certificates, or primary school certificate or lower secondary education; (2) medium education - upper secondary education or high school graduation; and (3) high education - university degree or postgraduate. Marital status was categorised into 'living with a spouse or a partner in the same household' and 'living as single'. We also included a rural/urban variable to proxy the potential lack of access to formal care services and social services for individuals living in rural areas. The following question was asked: 'How would you describe the area where you live: a big city; the suburbs or outskirts of a big city; a large town; a small town; a rural area or village?'. We dichotomised the variable into urban and rural, the latter including only people living in a rural area or village.

Finally, among the independent variables, we considered informal care received from children. By informal care, we mean personal care (for example, dressing, bathing or showering, eating, getting in or out of bed, and using the toilet), practical household help (for example, home repairs, gardening, transportation, shopping and household chores) and help with paperwork (for example, filling out forms and settling financial or legal matters). We built a binary variable that takes the value 1 if the respondent answered that he/she received informal care from a child on at least a weekly basis during the year of the interview.

\section{Results}

Table 1 presents summary statistics of the main variables used in the model for the whole sample, while Table E in Appendix III online does so for the

TABLE 1

Descriptive statistics: overall sample

\begin{tabular}{|c|c|c|c|c|c|}
\hline Variable & Description & Mean & Std dev. & Min. & Max. \\
\hline \multicolumn{6}{|l|}{ Utilisation } \\
\hline $\begin{array}{l}\text { Personal } \\
\quad \text { nursing care }\end{array}$ & $\begin{array}{l}1 \text { if you received any of the } \\
\text { following forms of home care } \\
\text { during the last } 12 \text { months: } \\
\text { professional or paid nursing or } \\
\text { personal care; meals on wheels }\end{array}$ & 0.07 & 0.26 & 0 & 1 \\
\hline $\begin{array}{l}\text { Paid domestic } \\
\text { help }\end{array}$ & $\begin{array}{l}1 \text { if you received professional or } \\
\text { paid home help during the last } 12 \\
\text { months, for domestic tasks that } \\
\text { you could not perform yourself } \\
\text { due to health problems }\end{array}$ & 0.09 & 0.28 & 0 & 1 \\
\hline
\end{tabular}


TABLE 1

Continued

\begin{tabular}{|c|c|c|c|c|c|}
\hline Variable & Description & Mean & Std dev. & Min. & Max. \\
\hline \multicolumn{6}{|l|}{ Need variables } \\
\hline Age & Age in years & 74.15 & 6.28 & 66 & 104 \\
\hline Female & 1 if female & 0.53 & 0.49 & 0 & 1 \\
\hline Health conditions & $\begin{array}{l}\text { Number of health } \\
\text { conditions out of } \\
16 \text { listed }\end{array}$ & 2.03 & 1.60 & 0 & 10 \\
\hline $\begin{array}{l}\text { Self-reported } \\
\text { health }\end{array}$ & $\begin{array}{l}\text { Self-reported health on a } \\
\text { scale from } 1 \text { to } 5(1= \\
\text { excellent; } 5=\text { poor })\end{array}$ & & & & \\
\hline 1. excellent & & 0.06 & 0.24 & 0 & 1 \\
\hline 2. very good & & 0.14 & 0.34 & 0 & 1 \\
\hline 3. good & & 0.36 & 0.48 & 0 & 1 \\
\hline 4. fair & & 0.31 & 0.46 & 0 & 1 \\
\hline 5. poor & & 0.11 & 0.32 & 0 & 1 \\
\hline Symptoms & $\begin{array}{l}\text { Number of symptoms out } \\
\text { of } 11 \text { listed }\end{array}$ & 2.03 & 2.00 & 0 & 11 \\
\hline Mobility & $\begin{array}{l}\text { Number of functional } \\
\text { limitations out of } 10 \\
\text { listed }\end{array}$ & 2.06 & 2.46 & 0 & 10 \\
\hline \multicolumn{6}{|l|}{ Non-need variables } \\
\hline Equivalent income & In euros per year & $4,337.84$ & $7,553.73$ & 83.67 & $330,955.00$ \\
\hline Informal care & $\begin{array}{l}1 \text { if you received (on a } \\
\text { weekly basis) any of the } \\
\text { following forms of } \\
\text { informal care during the } \\
\text { last } 12 \text { months: personal } \\
\text { care; practical } \\
\text { household help; help } \\
\text { with paperwork }\end{array}$ & 0.04 & 0.21 & 0 & 1 \\
\hline Low education & $\begin{array}{l}\text { No educational certificates, } \\
\text { or primary school } \\
\text { certificate or lower } \\
\text { secondary education }\end{array}$ & 0.60 & 0.48 & 0 & 1 \\
\hline Medium education & $\begin{array}{l}\text { Upper secondary education } \\
\text { or high school } \\
\text { graduation }\end{array}$ & 0.24 & 0.43 & 0 & 1 \\
\hline High education & $\begin{array}{l}\text { University degree or } \\
\text { postgraduate }\end{array}$ & 0.14 & 0.35 & 0 & 1 \\
\hline Retired & 1 if respondent is retired & 0.83 & 0.37 & 0 & 1 \\
\hline Rural & $\begin{array}{l}1 \text { if respondent reports } \\
\text { living in a rural area or } \\
\text { village }\end{array}$ & 0.48 & 0.49 & 0 & 1 \\
\hline
\end{tabular}

Source: SHARE wave 2, release 2.5.0; number of observations: 9,239. 
three models - Northern, Continental and Southern European - separately. Considering the whole sample, the mean age of respondents is 74 years, and 53 per cent of the sample are women. Around 7 per cent of those interviewed received personal nursing care in the baseline year, while 9 per cent of respondents received paid domestic help. We observe some differences in the use of home care services between the three areas. We find that 11 per cent of respondents received paid domestic help in the Northern countries, 10 per cent in Continental countries and 4 per cent in Southern Europe. Concerning the use of nursing care, we find that 5 per cent of respondents received this kind of care in Northern countries, 12 per cent in the Continental countries and 3 per cent in the Southern countries.

We will discuss the results separately for each type of formal home care considered in the analysis - low-skilled (paid domestic help) and skilled (nursing care). First, we show the Erreygers index estimates and then the decomposition results, which explain the contribution of individual factors to income-related inequality for each macro region. Tables $\mathrm{F}$ and $\mathrm{G}$ in Appendix III show the results from the univariate and bivariate probit models employed for the decomposition. In many cases, the bivariate model showed significant correlation coefficients between the error term of the structural equation for formal home care and the reduced form equation for informal care (see Appendix I). Hence, the decomposition results presented below were often based on the partial effect computed using the bivariate probit estimates. When the exogeneity condition was not rejected, the decomposition was based on the probit model. Estimates of correlation coefficients between the formal and informal care equations have been included in the notes to Tables $2 \mathrm{a}$ and $2 \mathrm{~b}$ for domestic help and personal nursing care, respectively.

\section{Domestic help}

Table 2a presents the estimates of the Erreygers indices, the partial effects and the inequality contributions by macro region for domestic help. Statistically significant coefficients, indices and contributions are indicated in bold.

The first two rows of the table report the overall Erreygers index (EI) and the Erreygers index adjusted for needs (ENA). The EI varies from $\mu-1$ to $1+\mu$ (where $\mu$ is the mean of the home care variable). A positive (negative) EI value indicates that better-off individuals are more (less) likely to use domestic help, regardless of needs. A positive (negative) ENA value indicates that better-off individuals are more (less) likely to use such services, after standardising for needs.

We find positive and significant pro-rich inequalities (measured by the EI) in the Continental (0.0714) and Southern European models (0.0485), while pro-rich inequalities also arise in the Northern European model, although they are much lower and not statistically significant $(0.0316)$. Despite these values 
TABLE $2 \mathrm{a}$

Contributions to inequality in the probability of using paid domestic help

\begin{tabular}{|c|c|c|c|}
\hline & Northern & Continental & Southern \\
\hline $\begin{array}{l}\text { Erreygers index (predicted) } \\
\text { Erreygers index (needs-adjusted) } \\
\text { Erreygers index (residual) }\end{array}$ & $\begin{array}{r}\text { Biprobit } \\
0.0316 \\
0.0325 \\
0.0333\end{array}$ & $\begin{array}{r}\text { Biprobit } \\
\mathbf{0 . 0 7 1 4} \\
\mathbf{0 . 0 7 1 0} \\
0.0695\end{array}$ & $\begin{array}{r}\text { Biprobit } \\
\mathbf{0 . 0 4 8 5} \\
\mathbf{0 . 0 5 0 6} \\
0.0492\end{array}$ \\
\hline \multicolumn{4}{|l|}{ Income } \\
\hline $\begin{array}{l}\text { Partial effect } \\
\text { Concentration index } \\
\text { Contribution } \\
\text { Contribution of income }\end{array}$ & $\begin{array}{r}-0.0001 \\
\mathbf{0 . 4 5 5 3} \\
-0.0042 \\
-0.0042\end{array}$ & $\begin{array}{r}-0.0001 \\
\mathbf{0 . 4 9 7 5} \\
-0.0088 \\
-0.0088\end{array}$ & $\begin{array}{r}-0.0001 \\
\mathbf{0 . 5 2 2 8} \\
-0.0074 \\
-0.0074\end{array}$ \\
\hline \multicolumn{4}{|l|}{ Need variables } \\
\hline $\begin{array}{l}\text { Partial effect } \\
\text { Concentration index } \\
\text { Contribution }\end{array}$ & $\begin{array}{r}\mathbf{0 . 0 0 1 7} \\
-\mathbf{0 . 0 0 7 2} \\
-0.0001\end{array}$ & $\begin{array}{r}\mathbf{0 . 0 0 1 5} \\
-\mathbf{0 . 0 0 7 2} \\
-0.0001\end{array}$ & $\begin{array}{r}0.0039 \\
-0.0108 \\
-0.0006\end{array}$ \\
\hline \multicolumn{4}{|l|}{ Mobility } \\
\hline Partial effect & 0.0032 & 0.0028 & 0.0015 \\
\hline Concentration index & -0.0150 & -0.0268 & $-\mathbf{0 . 0 3 5 2}$ \\
\hline $\begin{array}{l}\text { Contribution } \\
\text { Symptoms }\end{array}$ & \multicolumn{2}{|c|}{ Symptoms } & -0.0005 \\
\hline Partial effect & 0.0013 & 0.0015 & 0.0009 \\
\hline Concentration index & $-\mathbf{0 . 0 2 2 3}$ & -0.0162 & -0.0269 \\
\hline Contribution & -0.0002 & -0.0002 & -0.0002 \\
\hline \multicolumn{4}{|l|}{ Health conditions } \\
\hline Partial effect & 0.0004 & 0.0008 & 0.0021 \\
\hline Concentration index & -0.0156 & -0.0066 & -0.0108 \\
\hline \multicolumn{3}{|l|}{ Age } & -0.0002 \\
\hline Partial effect & 0.0012 & 0.0013 & 0.0010 \\
\hline Concentration index & -0.0006 & 0.0036 & -0.0015 \\
\hline Contribution & -0.0002 & 0.0014 & -0.0004 \\
\hline \multicolumn{4}{|l|}{ Female } \\
\hline Partial effect & -0.0009 & 0.0012 & -0.0010 \\
\hline Concentration index & 0.0005 & 0.0123 & 0.0204 \\
\hline Contribution & 0.0000 & 0.0000 & -0.0001 \\
\hline Contribution of need factors & -0.0009 & 0.0004 & -0.0021 \\
\hline \multicolumn{4}{|l|}{$\begin{array}{l}\text { Non-need variables } \\
\text { Informal }\end{array}$} \\
\hline Partial effect & -0.0075 & -0.0093 & -0.0131 \\
\hline Concentration index & -0.1684 & -0.1688 & -0.0264 \\
\hline Contribution & 0.0001 & 0.0003 & 0.0001 \\
\hline
\end{tabular}


TABLE 2a

Continued

\begin{tabular}{|c|c|c|c|}
\hline & Northern & Continental & Southern \\
\hline & Biprobit & Biprobit & Biprobit \\
\hline \multicolumn{4}{|l|}{ Low education } \\
\hline Partial effect & 0.0018 & -0.0025 & 0.0073 \\
\hline Concentration index & -0.0434 & -0.0875 & -0.0599 \\
\hline Contribution & -0.0001 & 0.0004 & -0.0015 \\
\hline \multicolumn{4}{|l|}{ High education } \\
\hline Partial effect & -0.0048 & -0.0069 & 0.0013 \\
\hline Concentration index & 0.1269 & 0.1918 & 0.4077 \\
\hline Contribution & -0.0004 & -0.0009 & -0.0001 \\
\hline \multicolumn{4}{|l|}{ Living with someone } \\
\hline Partial effect & -0.0229 & -0.0361 & $-\mathbf{0 . 0 3 2 7}$ \\
\hline Concentration index & -0.0795 & -0.1014 & -0.1018 \\
\hline Contribution & 0.0050 & 0.0095 & 0.0094 \\
\hline \multicolumn{4}{|l|}{ Retired } \\
\hline Partial effect & -0.0029 & -0.0022 & -0.0041 \\
\hline Concentration index & -0.0124 & 0.0329 & 0.0408 \\
\hline Contribution & 0.0001 & -0.0002 & -0.0004 \\
\hline \multicolumn{4}{|l|}{ Rural } \\
\hline Partial effect & -0.0029 & 0.0002 & -0.0073 \\
\hline Concentration index & -0.1123 & $-\mathbf{0 . 0 5 9 3}$ & -0.0669 \\
\hline Contribution & 0.0004 & -0.0001 & 0.0009 \\
\hline Contribution of non-need factors & 0.0051 & 0.0090 & 0.0083 \\
\hline Country fixed effects (contributions) & -0.0017 & 0.0013 & 0.0005 \\
\hline
\end{tabular}

Note: Decomposition based on a linear approximation using the average marginal effects from recursive bivariate probit. Significant partial effects, indices and contributions in bold $(\mathrm{p}<0.1)$. All models include country dummies.

Estimated correlation coefficients of domestic help equation with standard errors in parentheses:

- Northern: $0.659(0.198)$

- Continental: $0.699(0.136)$

- Southern: 0.894 (0.071)

being far from the upper bound of the index (1.09), they indicate that, overall, better-off individuals are more likely to use domestic help services. However, these results are not conclusive as regards the degree of horizontal inequity, because the index estimates did not take into account the distribution of needs. Therefore we report Erreygers indices adjusted for needs in the second row, which show that, in general, the pro-rich inequalities are reinforced. This means that needs are more concentrated among poor individuals.

Indeed, after adjusting for needs distribution, pro-rich inequalities increase in Northern and Southern Europe and they are high and statistically significant especially in Continental (0.0710) and Southern Europe (0.0506). Interestingly, 
in the Continental region, the needs-adjusted index is smaller than the overall index, due to the role of demographic factors such as age. ${ }^{28}$

Table 2a also shows decomposition results of the Erreygers index for the use of domestic help by macro region. Income-related inequality in the probability of using care in each macro region is decomposed into the contributions of household income, need factors and non-need factors.

The decomposition results reveal an interesting pattern of income-related inequalities in the use of domestic help and some similarities across the areas analysed. Indeed, both the direct contribution of income and the contribution of health needs are pro-poor in all macro areas. The direct contribution of income to overall inequalities is quite modest in all areas, while the contribution of needs ranges from -0.0021 in the Southern area to +0.0004 in the Continental area. The pro-poor contribution of income is due to the fact that its partial effect on the use of domestic help is negative while the concentration index is positive and statistically significant. Concerning demographic indicators, age and gender seem to have a small effect on the formation of overall incomerelated inequalities in Northern and Southern areas. Conversely, age is prorich concentrated and contributes positively to the formation of income-related inequalities in the Continental area. For this reason, the total contribution of needs to overall income-related inequalities is pro-rich in this area only.

The results also display a disproportionate concentration of needs among poor individuals, which is not sufficiently compensated for by a higher use of domestic help. Indeed, health need variables are all positively associated with the use of domestic help, and they are also highly concentrated among the poor. As a consequence, a redistribution of domestic help among people with higher health needs would reduce income-related inequalities. Among the set of health need variables, self-perceived health and mobility account for the main contribution to the overall index.

Turning to non-need factors, the decomposition exercise reveals that receiving informal domestic help positively contributes to the overall EI, although its contribution is significant in the Continental area only. The mechanism behind this result may be interesting. Indeed, as the negative sign of the partial effect suggests, informal care acts as a substitute for formal care. At the same time, informal care is highly concentrated among the poor, and this actually contributes to generating pro-rich inequalities in formal domestic help. A possible explanation may be the fact that individuals belonging to lower income groups may have financial difficulties in buying formal care services. Hence, they tend to turn to informal caregivers, and this actually contributes to increasing the gap in access to formal services between rich and poor and related inequalities.

\footnotetext{
${ }^{28}$ See also Figure A in Appendix III.
} 
Another factor contributing to the pro-rich inequality is marital status. Indeed, non-single respondents are more concentrated among low-income individuals (the generalised concentration indices are negative and significant in all three macro areas), and they receive paid domestic help less often. As a result, the contribution to income-related inequalities of being non-single is positive and significant in all cases. Marital status can also be considered a need variable in principle, because single respondents are evidently more vulnerable to the need for domestic help. In this analysis, we decided to consider only health problems or factors indirectly associated with such problems (demographics) among the needs variables. However, our results are not driven by this choice because pro-rich needs-adjusted inequalities also emerge if we include marital status among the need variables.

\section{Personal nursing care}

Table $2 b$ shows the Erreygers index estimates, the partial effects and the inequality contributions by macro area for the utilisation of professional nursing care.

Both the EI and the ENA are positive, fairly small (the upper bound of the EI is 1.07) and only statistically significant for the Continental model (the ENA). However, the decomposition exercise highlights some important differences across macro areas. In the Northern European model, we find that income is negatively associated with access to nursing care services, while it is positively associated with the same services in the Continental and Southern European models. Needs are distributed in a pro-poor fashion in all areas. As a consequence, we do not find horizontal inequity in the Northern European model, while we find pro-rich inequities in the other areas even though the ENA indices are very small and statistically significant in the Continental area only. ${ }^{29}$

Concerning the non-need variables, we find that less educated individuals consume a lower amount of formal care in Continental and Southern Europe, and this contributes positively to pro-rich inequalities in the use of such services in these areas. This is in line with the differences in the direct effect of income on the use of care across areas, as discussed before. The contribution of informal care to overall inequalities is quite modest, and this is mostly due to low substitutability with formal personal nursing care, which is a 'skilled' and more professional type of care.

To check the robustness of the results discussed above, we also used wealth and lagged income, instead of current income, as alternative living standard variables to rank individuals. Moreover, we also checked for the relevance of individual attitudes towards parents' care, changing the specification of the

\footnotetext{
${ }^{29}$ See also Figure B in Appendix III.
} 
TABLE $2 b$

Contributions to inequality in the probability of using personal nursing care

\begin{tabular}{|c|c|c|c|}
\hline & Northern & Continental & Southern \\
\hline & Biprobit & Probit & Probit \\
\hline Erreygers index (predicted) & 0.0023 & 0.0102 & 0.0024 \\
\hline Erreygers index (needs-adjusted) & 0.0036 & 0.0122 & 0.0059 \\
\hline Erreygers index (residual) & 0.0037 & -0.0086 & -0.0057 \\
\hline \multicolumn{4}{|l|}{ Income } \\
\hline Partial effect & -0.0002 & 0.0001 & 0.0001 \\
\hline Concentration index & 0.4553 & 0.4975 & 0.5228 \\
\hline Contribution & -0.0039 & 0.0047 & 0.0006 \\
\hline Contribution of income & -0.0039 & 0.0047 & 0.0006 \\
\hline \multicolumn{4}{|l|}{ Need variables } \\
\hline \multicolumn{4}{|l|}{ Self-assessed health } \\
\hline Partial effect & 0.0017 & 0.0255 & 0.0053 \\
\hline Concentration index & -0.0072 & -0.0072 & -0.0108 \\
\hline Contribution & -0.0001 & -0.0024 & -0.0008 \\
\hline \multicolumn{4}{|l|}{ Mobility } \\
\hline Partial effect & 0.0052 & 0.0156 & 0.0034 \\
\hline Concentration index & -0.0150 & -0.0268 & $-\mathbf{0 . 0 3 5 2}$ \\
\hline Contribution & -0.0004 & -0.0035 & -0.0013 \\
\hline \multicolumn{4}{|l|}{ Symptoms } \\
\hline Partial effect & 0.0024 & 0.0042 & 0.0019 \\
\hline Concentration index & -0.0223 & -0.0162 & -0.0269 \\
\hline Contribution & -0.0003 & -0.0005 & -0.0004 \\
\hline \multicolumn{4}{|l|}{ Health conditions } \\
\hline Partial effect & -0.0003 & 0.0041 & 0.0002 \\
\hline Concentration index & -0.0156 & -0.0066 & -0.0108 \\
\hline Contribution & 0.0000 & -0.0002 & -0.0001 \\
\hline \multicolumn{4}{|l|}{ Age } \\
\hline Partial effect & 0.0014 & 0.0049 & 0.0009 \\
\hline Concentration index & -0.0006 & 0.0036 & -0.0015 \\
\hline Contribution & -0.0002 & 0.0053 & -0.0004 \\
\hline \multicolumn{4}{|l|}{ Female } \\
\hline Partial effect & -0.0073 & -0.0206 & -0.0108 \\
\hline Concentration index & 0.0005 & 0.0123 & 0.0203 \\
\hline Contribution & -0.0001 & -0.0005 & -0.0004 \\
\hline Contribution of need factors & -0.0011 & -0.0019 & -0.0035 \\
\hline \multicolumn{4}{|l|}{ Non-need variables } \\
\hline \multicolumn{4}{|l|}{ Informal } \\
\hline Partial effect & -0.0155 & 0.0255 & -0.0016 \\
\hline Concentration index & -0.1684 & -0.1688 & -0.0264 \\
\hline Contribution & 0.0003 & -0.0009 & 0.0000 \\
\hline
\end{tabular}


TABLE $2 b$

Continued

\begin{tabular}{|c|c|c|c|}
\hline & Northern & Continental & Southern \\
\hline & Biprobit & Probit & Probit \\
\hline \multicolumn{4}{|l|}{ Low education } \\
\hline Partial effect & 0.0043 & -0.0212 & -0.0202 \\
\hline Concentration index & -0.0434 & -0.0875 & -0.0599 \\
\hline Contribution & -0.0004 & 0.0034 & 0.0041 \\
\hline \multicolumn{4}{|l|}{ High education } \\
\hline Partial effect & -0.0122 & -0.0256 & -0.0049 \\
\hline Concentration index & 0.1269 & 0.1918 & 0.4077 \\
\hline Contribution & -0.0011 & -0.0036 & -0.0003 \\
\hline \multicolumn{4}{|l|}{ Living with someone } \\
\hline Partial effect & -0.0281 & -0.0437 & -0.0001 \\
\hline Concentration index & -0.0795 & -0.1014 & -0.1018 \\
\hline Contribution & 0.0061 & 0.0115 & 0.0000 \\
\hline \multicolumn{4}{|l|}{ Retired } \\
\hline Partial effect & -0.0093 & 0.0046 & -0.0151 \\
\hline Concentration index & -0.0124 & 0.0329 & 0.0408 \\
\hline Contribution & 0.0004 & 0.0005 & -0.0017 \\
\hline \multicolumn{4}{|l|}{ Rural } \\
\hline Partial effect & -0.0045 & 0.0135 & -0.0087 \\
\hline Concentration index & -0.1123 & -0.0593 & -0.0669 \\
\hline Contribution & 0.0007 & -0.0018 & 0.0011 \\
\hline Contribution of non-need factors & 0.0060 & 0.0091 & 0.0031 \\
\hline Country fixed effects (contributions) & -0.0025 & 0.0069 & 0.0025 \\
\hline
\end{tabular}

Note: Decomposition based on a linear approximation using the average marginal effects from univariate and bivariate probit. Significant partial effects, indices and contributions in bold $(p<0.1)$. All models include country dummies.

Estimated correlation coefficients of personal nursing care equation with standard errors in parentheses:

- Northern: $0.766(0.205)$

- Continental: $0.040(0.220)$

- Southern: $0.512(0.262)$

probit / bivariate probit model used for the decomposition. Our main results remained substantially unchanged. All details of these robustness checks are reported in Appendix II online.

\section{Conclusions}

The purpose of the present study was to investigate the degree and determinants of income-related inequalities in the use of home care services among older people across three macro areas in Europe, which are highly heterogeneous in terms of the degree of public financing of LTC and the strength and social value 
of family ties. Our analysis sheds light on the role these factors play in shaping income-related inequalities in the use of LTC services. In order to analyse equity issues related to the provision of home care services, the empirical model was estimated by considering separately skilled (nursing care) and lowskilled (paid domestic help) formal home care. Since in both cases the measure for formal home care access was a binary variable, indicating whether or not respondents had any formal home care utilisation, we used the corrected version of the Erreygers concentration index (2009a and 2009b). We decomposed the Erreygers index into the contribution of income, need and non-need factors. Among the non-need factors, we included informal care. We addressed how informal care by children and formal home care interact, building the Erreygers index decomposition on a recursive bivariate probit model, which controls for the potential simultaneity between formal home care and informal care.

Using cross-country comparative micro data from SHARE (the Survey of Health, Ageing and Retirement in Europe), we find important differences between the kind of care analysed ('skilled' versus 'unskilled') and the three macro areas considered. ${ }^{30}$ Concerning the kind of care, we find substantial horizontal equity or low and weakly statistically significant prorich inequities in the use of skilled home care, while we detect significant pro-rich inequities in the use of low-skilled domestic care in Continental and Southern Europe. In all areas, informal care services seem to act as a sort of safety net for the poor; in particular, we find that informal care substitutes for low-skilled formal care and appears to be disproportionately concentrated among the worse off, increasing the gap in access to these services between rich and poor individuals.

With respect to the differences between the three areas, our results show that in the Northern European model there is no violation of the horizontal equity principle in the provision of home care services. In these countries, indeed, the needs of the elderly for personal and domestic help are expected to be met by the state, which provides high public spending on universal, equitable services, including LTC public coverage. On the other hand, in the Continental European model, it appears that disadvantaged groups tend to face more difficulties in using home-based health care services. This result is also in accordance with the Esping-Andersen (1990) approach, in which conservative countries tend to preserve social inequality and limit the redistributive process. Finally, we find important inequities in the Southern European model, characterised by highly privatised LTC systems and an extensive role of family in the provision of LTC services.

Our results indicate that higher involvement of the state in the LTC sector is correlated with more equitable access to LTC services. When the

\footnotetext{
${ }^{30}$ These macro areas are Northern Europe (Denmark, the Netherlands and Sweden), Continental Europe (Austria, Belgium, France and Germany) and Southern Europe (Greece, Italy and Spain).
} 
provision of public LTC coverage is poor, important pro-rich inequities may arise. In this respect, the situation seems to be particularly worrying for the Southern European countries, in which LTC public insurance is weak and informal support for the elderly has been pivotal. ${ }^{31}$ However, women's new economic role and contribution to family welfare due to their higher labour force participation is threatening the 'Southern family model', and unpaid care provided by relatives can no longer be taken for granted. More generally, the increasing demand for care, in combination with a reduced potential for informal care, is likely to result in a need to expand public LTC coverage. Higher state involvement in the financing of LTC services may produce important social benefits. It may be desirable to guarantee equity of access to LTC services, while also encouraging the labour market supply of grown-up children who are often engaged in informal care assistance to their elderly parents. In our analysis, we show that recourse to informal care is more pronounced for the 'unskilled' type of care. For this reason, public resources directed to the LTC sector might be more concentrated on this kind of care in the future.

Of course, the complete replacement of informal care by formal care is not financially feasible, since the public financial resources available to pay for public LTC assistance are continuously decreasing. ${ }^{32}$ An interesting compromise that may help achieve both equity of access and sustainable public expenditure in the LTC sector is community care, which is less costly than institutional LTC and appears to be a sensible way of responding to elderly people's needs while also averting demographic and economic crisis. Several European countries are aiming to stimulate community living and care, including home care, as a sustainable approach to ease the burden of care on family members and to prevent the need for long-term institutionalisation. The elderly are thought to prefer being cared for in their own homes, where they are presumed to be surrounded by family, friends and others who know and understand them. A rearrangement of the LTC sector to favour community care might be necessary in light of the already urgent problem of demographic ageing, which will inevitably become more pronounced in the near future.

\section{Supporting information}

Additional supporting information may be found in the online version of this paper on the publisher's website:

- Appendices I-III

\footnotetext{
${ }^{31}$ Costa-Font and Zigante, 2014.

${ }^{32}$ Costa-Font, 2010a and 2010b.
} 


\section{References}

Balia, S. and Brau, R. (2013), 'A country for old men? Long-term home care utilization in Europe', Health Economics, vol. 23, pp. 1185-212.

Bolin, K., Lindgren, B. and Lundborg, P. (2008), 'Informal and formal care among single-living elderly in Europe', Health Economics, vol. 17, pp. 393-409.

Bonsang, E. (2009), 'Does informal care from children to their elderly parents substitute for formal care in Europe?', Journal of Health Economics, vol. 28, pp. 143-54.

Börsch-Supan, A. and Jürges, H. (eds) (2005), The Survey of Health Ageing and Retirement in Europe: Methodology, Mannheim: Mannheim Research Institute for the Economics of Aging.

Brenna, E. and Di Novi, C. (2015), 'Is caring for elderly parents detrimental to women's mental health? The role of the European North-South gradient', Review of Economics of the Household, vol. 14, pp. 745-78.

Breyer, F. and Felder, S. (2006), 'Life expectancy and health care expenditures: a new calculation for Germany using the costs of dying', Health Policy, vol. 75, pp. 178-86.

Carrieri, V. and Wuebker, A. (2013), 'Assessing inequalities in preventive care use in Europe', Health Policy, vol. 113, pp. 247-57.

Charles, K. K. and Sevak, P. (2005), 'Can family caregiving substitute for nursing home care?', Journal of Health Economics, vol. 24, pp. 1174-90.

Costa-Font, J. (2010a), 'Devolution, diversity and welfare reform: long-term care in the "Latin Rim"', Social Policy and Administration, vol. 44, pp. 481-94.

- (2010b), 'Family ties and the crowding out of long-term care insurance', Oxford Review of Economic Policy, vol. 26, pp. 691-712.

- and Zigante, V. (2014), 'Long term care coverage in Europe: a case for "implicit insurance partnerships"', LSE Health, Working Paper no. 37/2014.

Crespo, L. and Mira, P. (2010), 'Caregiving to elderly parents and employment status of European mature women', CEMFI, Working Paper no. 1007.

- and - (2014), 'Caregiving to elderly parents and employment status of European mature women', Review of Economics and Statistics, vol. 96, pp. 693-709.

de Meijer, C., Koopmanschap, M., Bago d'Uva, T. and van Doorslaer, E. (2011), 'Determinants of long-term care spending: age, time to death or disability?', Journal of Health Economics, vol. 30, pp. 425-38.

Denton, F. T. and Spencer, B. G. (2010), 'Chronic health conditions: changing prevalence in an aging population and some implications for the delivery of health care services', Canadian Journal on Aging, vol. 29, pp. 11-21.

Department of Health (2009), Tackling Health Inequalities: 10 Years On, London, http:// www.dh.gov.uk/en/Publicationsandstatistics/Publications/PublicationsPolicyAndGuidance/ DH_098936.

Di Novi, C., Jacobs, R. and Migheli, M. (2015), 'The quality of life of female informal caregivers: from Scandinavia to the Mediterranean Sea', European Journal of Population, vol. 31, pp. 1-27.

-, Piacenza, M., Robone, S. and Turati, G. (2015), 'How does fiscal decentralization affect regional disparities in well-being? Evidence from health inequalities in Italy', University of York, Health, Econometrics and Data Group (HEDG), Working Paper no. 15/23.

Duan, N., Manning, W., Morris, C. and Newhouse, J. (1984), 'Choosing between the sample selection model and the multi-part model', Journal of Business Economics and Statistics, vol. 2, pp. 283-9.

Erreygers, G. (2009a), 'Correcting the concentration index', Journal of Health Economics, vol. 28 , pp. 504-15. 
- (2009b), 'Correcting the concentration index: a reply to Wagstaff', Journal of Health Economics, vol. 28, pp. 521-4.

- and van Ourti, T. (2011), 'Measuring socioeconomic inequality in health, health care and health financing by means of rank-dependent indices: a recipe for good practice', Journal of Health Economics, vol. 30, pp. 685-94.

Esping-Andersen, G. (1990), The Three Worlds of Welfare Capitalism, Princeton, NJ: Princeton University Press.

Eurostat (2012), Demography Report 2010.

Idler, E. L. and Benyamini, Y. (1997), 'Self-rated health and mortality: a review of twentyseven community studies', Journal of Health and Social Behavior, vol. 38, pp. 2137.

Jusot, F., Or, Z. and Sirven, N. (2012), 'Variations in preventive care utilization in Europe', European Journal of Ageing, vol. 9, pp. 15-25.

Kennedy, B. P., Kawachi, I., Glass, R. and Prothrow-Stith, D. (1998), 'Income distribution, socioeconomic status, and self rated health in the United States: multilevel analysis', $B M J$, vol. 317, pp. 917-21.

Kjellsson, G. and Gerdtham, U-G. (2013), 'On correcting the concentration index for binary variables', Journal of Health Economics, vol. 32, pp. 659-70.

Lorant, V., Boland, B., Humblet, P. and Deliege, D. (2002), 'Equity in prevention and health care', Journal of Epidemiology and Community Health, vol. 56, pp. 510-16.

Mingione, E. (2001), 'The Southern European welfare model and the fight against poverty and social exclusion', in M. K. Tolba (ed.), Our Fragile World: Challenges and Opportunities for Sustainable Development, Oxford: EOLSS Publications.

Nagi, S. N. (1976), 'An epidemiology of disability among adults in the United States', Milbank Memorial Fund Quarterly: Health and Society, vol. 54, pp. 439-67.

Seshamani, M. and Gray, A. (2004), 'Ageing and health-care expenditure: the red herring argument revisited', Health Economics, vol. 13, pp. 303-14.

Stearns, S. C. and Norton, E. C. (2004), 'Time to include time to death? The future of health care expenditure predictions', Health Economics, vol. 13, pp. 315-27.

Undén, A. L. and Elofsson, S. (2006), 'Do different factors explain self-rated health in men and women?', Gender Medicine, vol. 3, pp. 295-308.

van Doorslaer, E., Koolman, X. and Jones, A. (2004), 'Explaining income-related inequalities in doctor utilisation in Europe', Health Economics, vol. 13, pp. 629-47.

- Masseria, C. and Koolman, X. (2006), 'Inequalities in access to medical care by income in developed countries', CMAJ, vol. 174, pp. 177-83.

- and van Ourti, T. (2011), 'Measuring inequality and inequity in health and health care', in P. Smith and S. Glied (eds), The Oxford Handbook of Health Economics, Oxford: Oxford University Press.

- and Wagstaff, A. (2000), 'Equity in the delivery of health care in Europe and the US', Journal of Health Economics, vol. 19, pp. 553-83.

Van Houtven, C. H. and Norton, E. C. (2004), 'Informal care and health care use of older adults', Journal of Health Economics, vol. 23, pp. 1159-80.

Wagstaff, A. (2005), 'The bounds of the concentration index when the variable of interest is binary, with an application to immunization inequality', Health Economics, vol. 14, pp. 429-32.

— and van Doorslaer, E. (2000), 'Equity in health care finance and delivery', in A. J. Culyer and J. P. Newhouse (eds), Handbook of Health Economics, vol. 1A, Amsterdam: Elsevier.

- , - and Paci, P. (1991), 'On the measurement of horizontal inequity in the delivery of health care', Journal of Health Economics, vol. 10, pp. 169-205.

Zweifel, P., Felder, S. and Meiers, M. (1999), 'Ageing of population and health care expenditure: a red herring?', Health Economics, vol. 8, pp. 485-96. 